Revista Monografias Ambientais - REMOA v. 14, 2015, p. 143-154

\title{
A Inclusão de crianças com necessidades educacionais especiais na prática pedagógica de uma escola municipal do município de Vila Nova do Sul
}

La inclusión de los niños con necesidades educativas especiales en la práctica pedagógica de una escuela municipal en el municipio de Vila Nova do Sul

\section{Sabrina Neves Saldanhaㄹ, Carlos Alberto Xavier Garcia², Patrícia Zaupa ${ }^{3}$}

${ }^{1}$ Pós Graduanda do Curso de Educação: Interdisciplinaridade e Transversalidade, Universidade Federal do Pampa, São Gabriel, RS, Brasil.

${ }^{2}$ Mestre em Educação, Núcleo de Desenvolvimento Educacional, Federal do Pampa, São Gabriel, RS, Brasil. ${ }^{3}$ Especialista em Inclusão, Núcleo de Desenvolvimento Educacional, Federal do Pampa, São Gabriel, RS, Brasil.

\section{Resumo}

Este trabalho tem por objetivo trabalhar a socialização, humanização e orientação dos professores e funcionários sobre a importância da inclusão escolar, bem como analisar as relações sobre a inclusão na escola e identificar as principais barreiras reconhecidas para a inserção de al unos com necessidades educacionais especiais em turmas de ensino regular. Os procedimentos metodológicos constituíram em um plano de intervenção composto por oficinas, entrevista e uma palestra. A análise apontou que os educadores da escola pública municipal de Vila Nova do Sul possuem uma visão de integração e não de inclusão e reconhecem a falta de formação, políticas públicas e comprometimento para que a inclusão ocorra,de fato. Dessa forma, embora muito se tenha falado sobre Inclusão Escolar, esse processo vai além do simples ato de colocar um aluno com NEE dentro da escola regular, essa ação deve prever um comprometimento coletivo da escola e dos agentes envolvidos, bem como um projeto-políticopedagógico e o planejamento da formação continuada para os servidores da educação. Assim, conclui-se que com formação e comprometimento a educação inclusiva mesmo com sua complexibilidade poderá acontecer de maneira coerente contribuindo assim para mudar a sociedade, incluindo seus cidadãos de maneira mais justa.

Palavras-chave: Inclusão; Formação; Alunos com NEE.

\section{Resumen}

Esta investigación tiene por objetivo trabajar la socialización, humanización y orientación de los profesores y operarios sobre la importancia de la inclusión escolar, así como analizar las relaciones sobre la inclusión en la escuela e identificar las principales barrera reconocidas pela inserción de alumnos con necesidades educacionales especiales en turmas de enseñanza regular. Los procedimientos metodológicos constituyen en un plan de intervención, compuesto por talleres, entrevista y una charla. El análisis apuntó que loseducadores de la escuela municipal de Vila Nueva del Sur posen una visión de integración y no de inclusión y reconocen la falta de formación, políticas públicas y comprometimiento para que la inclusión ocurra de hecho. De esa forma aun que muy se haya hablado sobre la inclusión escolar, ese proceso va además el simple acto de colocar un alumno con NEE dentro de la escuela regular, esa acción debe prever un comprometimiento colectivo de la escuela y de los agentes envueltos, así como unproyecto-político pedagógico y planificación de la formación continuada para los servidores de la educación. Así, se concluyeque con formación y comprometimiento la educación inclusiva aún con su complexibilidade podrá acontecer de manera coherente contribuyendo así para cambiar la sociedad, incluyendo sus ciudadanos de manera más justa.

Palabras- clave: Inclusión, Formación; Alumnos con NEE 


\section{Introdução}

Nas últimas décadas, o discurso da inclusão escolar assumiu status privilegiado. Entretanto, existem diversas controvérsias entre as leis (o que seria o ideal) e a prática.

Há autores e profissionais que defendem a inclusão escolar como parte integrante de um movimento maior de inclusão social que deve atuar na educação pela universalização do acesso e pela igualdade de ensino.

Conforme Selau (2007, p.24):

A Educação Inclusiva é sinônimo de que todas as crianças, independentemente de quais forem às necessidades que possam apresentar, ou mesmo aquelas com altas habilidades, devam estar na mesma sala de aula, tendo acesso ao ensino formal. Todas devem participar do processo educacional tradicionalmente conhecido, sem separações.

Há também aqueles, pouco informados, que têm interpretado a inclusão escolar como mero acesso de alunos com Necessidades Educacionais Especiais (NEE) às escolas regulares, apenas com a necessidade de ouvir professores, isso se deve ao fato de que muitos estudos têm sido feitos na área da inclusão e pouca mudança tem se percebido na prática, pois, mais do que criar condições para os alunos com NEE, a inclusão é um desafio que implica mudar a escola como um todo. É valorizar as peculiaridades de cada aluno, atender a todos na escola, incorporar a diversidade, sem nenhum tipo de distinção. A inclusão é um processo cheio de imprevistos, sem fórmulas prontas e que exige aperfeiçoamento constante.

Dessa forma levanta-se uma questão fundamental: Como fazer a Inclusão de crianças com NEE na prática pedagógica de uma escola municipal do município de Vila Nova do Sul?

\section{Justificativa}

Este trabalho busca discutir a prática pedagógica e possíveis soluções para que a inclusão ocorra de fato. Mesmo com grandes dificuldades enfrentadas por pessoas com NEE no uso do seu poder de cidadão, incluir é oferecer o desenvolvimento da autonomia, por meio da colaboração de aprendizagens para agir nas diferentes circunstâncias da vida.

A partir de leituras realizadas podemos destacar os vários meios existentes para que os alunos com NEE façam parte hoje da sociedade, através de incentivos fiscais, tais como programas de incentivo do governo que servem para formação de profissionais, infraestrutura adequada e a mobilização da escola e da sociedade em geral para que se busque um ensino de qualidade para todos os alunos inclusive os com NEE.

A sociedade brasileira passou por diversas etapas e através de estudos, moldou sua forma de relacionar-se com o que considerava "diferente da normalidade". Dessa forma passou por um processo de etapas históricas que Selau (2007, p.14) denomina: exclusão, atendimento segregado, interação, e educação inclusiva.

Embora estejam hoje na educação inclusiva, os alunos com NEE mesmo amparadas por lei, na maioria das vezes, não conseguem ser incluídas de fato na escola regular e vários são os fatores para 
esse fracasso o que gera a exclusão desses alunos, o que para o autor (2007, p.13) se explica porque há intenção de incluir, inclusive na escola, mas a sociedade age de maneira ambígua e dupla excluindo e incluindo ao mesmo tempo.

Dessa forma é comum escutar os clichês "Desculpe não estamos preparados parareceber seu filho".Essa é a resposta que muitos pais ouvem ao tentar matricular um filho com Necessidades Educacionais Especiais (NEE) numa escola regular. Com tantos avanços tecnológicos na comunicação, medicina e na educação, A Inclusão se faz necessária todos os dias e a cada ano com novas práticas educacionais, que procuram integrar os alunos com NEE.

Do contrário cairemos em práticas "sutis" de exclusão como aquelas que são cometidas a todo o momento. Conforme Bento Selau (2007, p.16) exclusão é algo existente e inacabável, algo que qualquer pessoa pode fazer, mesmo sem notar alguma coisa que se deve policiarnos próprios atos e também nos alunos. Por isso deve-se tentar reconhecê-la, para se tentar evitá-la.

Sendo assim, de acordo com a Declaração de Salamanca (1994):

As escolas devem acolher todas as crianças, independentemente de suas condições físicas, intelectuais, sociais, emocionais, linguísticas ou outras. Devem acolher crianças com deficiência e crianças bem dotadas; crianças que vivem nas ruas e que trabalham; crianças de populações distantes ou nômades; crianças de minorias linguísticas, étnicas ou culturais e crianças de outros grupos ou zonas desfavorecidas ou marginalizadas. (DECLARAÇÃO DE SALAMANCA p. 17-18)

Além da Declaração de Salamanca temos ainda os preceitos constitucionais que determinam que o direito à educação das pessoas com NEEdeverá ser garantido pelo Estado por meio de um "atendimento educacional especializado aos portadores de deficiência, preferencialmente na rede regular de ensino" (artigo 208, Inciso III, da Constituição Federal).

O artigo 20, da Lei Federal n.. 7.853, de 1989, que dispõe sobre o apoio às pessoas com deficiência, e também que ao Poder Público e seus órgãos cabe assegurar às pessoas com deficiência o pleno exercício de seus direitos básicos, inclusive dos direitos à educação.

Contudo, ainda assim, a educação dos alunos com NEE, não é um assunto que possa ser resolvido somente através de leis e acordos, uma marca registrada de nossa cultura que acredita que se pode mudar a realidade com a criação de leis.

Nessa perspectiva, Beyer apud Selau diz:

No confronto entre legislação e realidades transparece o sentimento de incompletude das redes de ensino e professores, para fazer cumprir essa proposta. Faltam compreensões sobre a proposta, didáticas e metodologias apropriadas, bem como condições de trabalho aos educadores. A legislação sobre educação escolar inclusiva no Brasil, bem como a sustentabilidade das ideias, é recentemente e, possivelmente, será alvo de discussões como também de mudanças. 
Mesmo se tratando de um tema tão discutido em encontros de educadores, percebe-se, porém, a falta de relação entre a teoria, muito estudada, e as práticas dos educadores que na maioria das vezes não obtém êxito.

\section{Metodologia}

O objetivo desta pesquisa intitulada "A Inclusão de crianças com necessidades educacionais especiais na prática pedagógica de uma escola municipal do município de Vila Nova do Sul”, que aqui se apresenta é trabalhar a socialização, humanização e orientação dos professores e funcionários sobre a importância da inclusão escolar, bem como analisar as relações sobre a inclusão na escola e identificar as principais barreiras para a inserção de alunos com NEE em turmas de ensino regular.

A pesquisa de caráter qualitativa com estudo de caso foi desenvolvida em uma escola da rede pública, e desenvolveu-se sob a orientação do Professor Ms. Carlos Alberto Xavier Garcia, professor do Curso de Pós Graduação em Educação: Interdisciplinaridade e Transversalidade, e co orientadora Professora Especialista Patrícia Zaupa, em nível de Especialização na Universidade Federal do Pampa - Campus São Gabriel.

Desenvolveram-se atividades básicas da de indagação e observação da realidade com estudo bibliográfico, pois a pesquisa vincula pensamento e ação.

Pensar em pesquisa qualitativa é pensar em tudo aquilo que não pode ser mensurável, pois a realidade e o sujeito são elementos inseparáveis. Assim sendo, quando se trata do sujeito, levam-se em consideração seus traços subjetivos e suas particularidades. Com base nesse princípio, afirma-se que a pesquisa qualitativa tem um caráter exploratório, uma vez que estimula o entrevistado a pensar e a se expressar livremente sobre o assunto em questão. Na pesquisa qualitativa, os dados, em vez de serem tabulados, de forma a apresentar um resultado preciso, serão retratados por meio de relatórios, levandose em conta aspectos tidos como relevantes, como as opiniões e comentários do público entrevistado.

Os procedimentos metodológicos constituíram-se em um plano de intervenção composto por oficinas, entrevista semi estruturada e uma palestra dialogada. Foram utilizados como materiais de apoio um poema; uma charge; um vídeo, bem como aparelho de multimídia. Participaram da pesquisa os profissionais da educação de uma escola de ensino fundamental do município de Vila Nova do Sul. A entrevista semi estruturada foi transcrita em forma de análise de discurso com Análise em Prosa.

De acordo com Silva e Alves (1992) "são fatos inquestionáveis que as entrevistas semiestruturadas, em que o discurso dos sujeitos foi gravado e transcrito na íntegra, produzem um volume imenso de dados que se acham extremamente diversificados pelas peculiaridades da verbalização de cada um".

Dessa maneira foram criados para análise do discurso núcleos de significação com comparações e discussões a partir das respostas obtidas, conforme fundamentação teórica da pesquisa qualitativa de estudo de caso.

\subsection{Caracterização do objeto da pesquisa}


O estudo foi realizado com profissionais da educação (professores e gestão escolar) do ensino fundamental, em uma (01) escola pública do município de Vila Nova do Sul. Foi aplicada uma pesquisa contendo perguntas objetivas com os seguintes temas: crianças incluídas acessibilidade ao ambiente escolar; existência de projeto específico de inclusão para atender aos alunos incluídos; preconceito entre os alunos com NEE e os demais; ambiente de aprendizagem favorecedor; conhecimento dos profissionais de educação sobre o conceito de NEE (etiologia, características, tipos; existência de profissionais especializados; contato e trocas de experiências entre as escolas e os profissionais da saúde; existência de atividades diferenciadas e acompanhamento pedagógico).

A entrevista foi semi estruturada, contendo 08 questões elaboradas pela própria pesquisadora. Contribuiu nas respostas das entrevistas, a gestão escolar composta pela diretora, às duas vices diretoras, e a coordenadora pedagógica, bem como a uma professora da Educação Infantil, uma professora dos Anos Iniciais (pedagogia), Uma professora de Filosofia, uma professora de Língua Portuguesa, uma professora de Educação Especial (sala de recursos) e para a palestra os professores e funcionários da escola.

As oficinas bem como a palestra com uma Professora Ms. em Educação Inclusiva buscaram disseminar novas práticas pedagógicas com responsabilidade e comprometimento na tarefa de ensinar, afim de que os alunos com NEE tenham de fato um aprendizado significativo. Conforme André (2001, p.58)

O que se espera dos professores? Que eles assumam de forma competente e responsável sua tarefa de ensinar, a fim de que a grande maioria de seus alunos desenvolva uma atividade intelectual significativa, apropriando-se de conhecimentos fundamentais, para a inserção comprometida e ativa na sociedade.

Esta pesquisa foi desenvolvida através de um Plano de Intervenção junto com um grupo comprometido de educadores que discutem e buscam alternativas para a educação inclusiva na rede Municipal de Educação de Vila Nova do Sul.

Assim acreditamos que nossos alunos com NEE possam ter uma educação de qualidade tornando-se cidadãos plenos, superando seus limites e se sobressaindo nas questões do dia a dia.

\subsection{Educação Inclusiva na rede municipal de Vila Nova do Sul}

A educação pública, no município atende a um número de 461 alunos sendo 15 alunos da Educação Inclusiva, segundo o último censo escolar. O município atualmente abrange uma Escola de Educação Infantil e uma Escola de Ensino Fundamental (lócus desta pesquisa), a referida escola atende desde a pré-escola até o nono ano. Os alunos matriculados são residentes no interior e também na cidade, sendo que em grande parte os pais são trabalhadores da indústria do calcário, atuam no comércio, outros são funcionários da Prefeitura Municipal ou são trabalhadores do Campo, em sua maioria advindos de família com poucas condições financeiras.

A Educação no município começou receber alunos com NEE a partir de 2006, quando a LDB lei $\mathrm{N}^{\circ}$ 9394/96 garantiu o acesso dos alunos portadores de NEE na escola regular desde aquela data. No entanto na escola em estudo a partir de 2006 passou a atender alunos com NEE que freqüentavam a Escola da Associação de Pais e Amigos dos Excepcionais em São Gabriel (APAE-SG). 
Na ocasião não havia estrutura para atender os alunos especiais e então foi designada uma professora com experiência em Educação Especial para dar suporte pedagógico e então improvisou o material e trabalhou com o que tinha.

No ano seguinte, 2007 com o levantamento no censo escolar feito com base nas informações do ano anterior, o Ministério da Educação (MEC), enviou o material necessário para a sala de recursos da Escola em estudo, com o objetivo de qualificar o atendimento especializado para os alunos com NEE naquela Instituição.

\section{Resultados e Discussão}

Para a análise dos dados foram consideradas as percepções do pesquisador a partir das três oficinas oferecidas sobre Inclusão Escolar e Educação e durante uma palestra dialogada sobre Inclusão, sensibilidade e Educação.

A pesquisa teve um total de 30 (trinta) pessoas participantes das atividades do Plano de Intervenção e os pré requisitos para participarem desta avaliação qualitativa era a de serem professores do município e trabalhar com as diversidades. Procedeu-se uma entrevista com 10 professores da rede municipal, aplicada individualmente a partir do tema Educação Inclusiva e que participaram das oficinas sobre este tema.

Conforme os gráficos abaixo o universo da pesquisa trabalhou com o público composto por trinta (30) professores e funcionários da educação; vinte e dois (22) professores e um (1) funcionário de escola que participaram da palestra sobre Inclusão e dez (10) professores participaram das oficinas e da entrevista.

O número de professores com pós graduação é de vinte três (23); com pós graduação em outras áreas são dois (2) e quatro (4) professores não possuem pós graduação e apenas uma (1) professora possui graduação em educação especial.

O número de alunos matriculados é de quatrocentos e sessenta e três (463), sendo que quinze (15) destes alunos possuem necessidades educacionais especiais.

Gráfico 1: Professores participantes da pesquisa

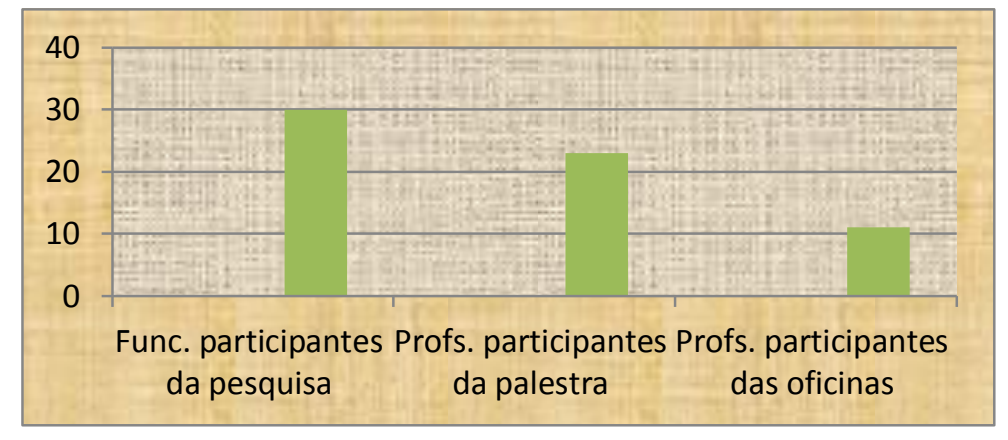

Fonte: Autores, 2015.

Gráfico 2: formação dos professores pesquisados 


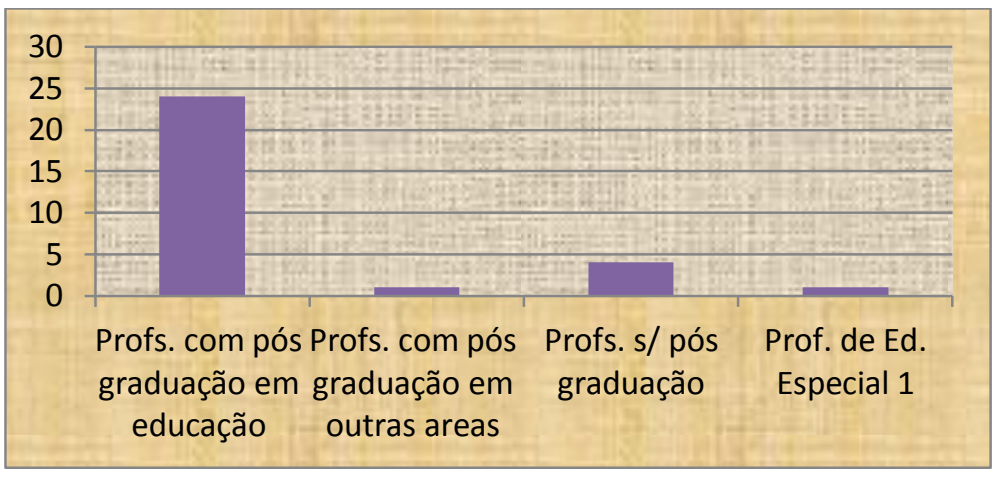

Fonte: Autores, 2015.

Gráfico 3:Quadro de alunos matriculados na escola pesquisada

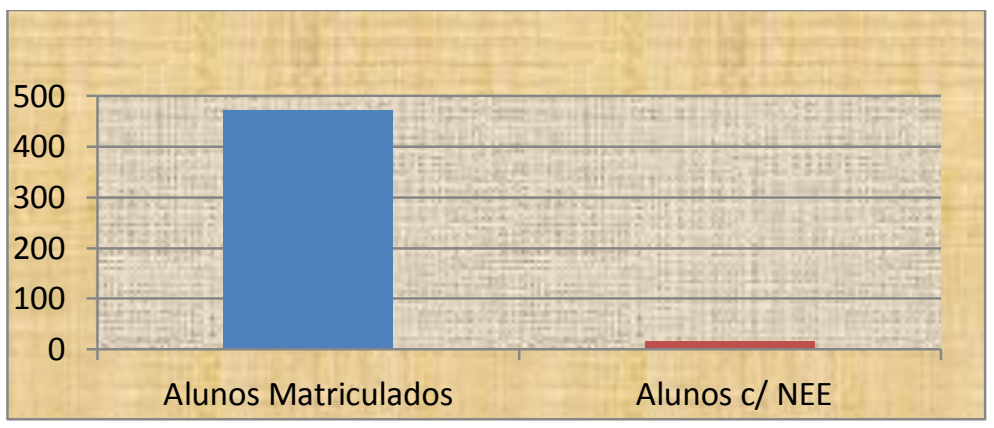

Fonte: Autores, 2015.

Para análise dos resultados foi feita análise em prosa com cinco núcleos de significação, que constam de cinco perguntas com relação ao preparo profissional, significado de inclusão e integração; sentimento preconceituoso; inteligência e habilidades e perspectivas de uma nova sociedade com inclusão. A análise procura cumprir com os objetivos propostos na pesquisa, considerando a educação continuada como fundamental para a Educação Inclusiva. Seguem os núcleos de significação:

\section{1) O professor está preparado para inclusão?}

Num primeiro momento observamos que os professores possuem discursos similares que se completam, conforme recortes:

Professora D.S.C.: "Eu diria que não, mas isso não é uma regra geral. Os recursos existem com boa vontade e uma visão mais ampla sobre a inclusão a escola também de oportunidade aos seus professores em qualificá-los, já é um bom começo. Certamente a escola terá um retorno positivo. Sabemos que existem pessoas preparadas e que fazem sua parte, mas ainda é uma minoria". 
Os discursos se complementam e são similares, percebemos que todos concordam que não estamos preparados integralmente e que além de formação há falta de comprometimento.

Professora S.T.N.: "Não estamos preparados, mas o professor deve buscar soluções para cada caso. Depende da disciplina que trabalhamos".

Professora A.M.R.: "Alguns, porém enquanto não estiverem todos preparados ainda existirá exclusão".

As professoras aqui possuem conceitos de inclusão marcados pela similaridade, quando perguntadas sobre inclusão todas concordam com a dificuldade da implantação, mas são unânimes, em afirmar que com comprometimento esse processo se torna menos complexo.

Conforme Freire (1996, p. 24):

Quando vivenciamos a autencidade exigida pela prática de ensinar-aprender participamos de uma experiência total, diretiva, política, ideológica, pedagógica, estética e ética em que a boniteza deve achar-se de mãos dadas com a decência e com a seriedade.

Dessa forma com comprometimento e sensibilidade podemos compreender e trabalhar a inclusão enxergando a beleza da educação inclusiva deixando de lado as formas cruéis de exclusão e preconceito das quais vivenciamos na escola.

2) Fala-se muito também na integração dos alunos com necessidades educacionais especiais. Existe diferença entre inclusão e integração?

A integração se refere à necessidade de modificar a pessoa com NEE, de maneira que esta possa vir a se identificar, com os demais para então poder ser inserida, associada, a convivência igualitária em sociedade, já a Inclusão não é um processo que envolva somente um lado, mas abrange duas direções, envolvendo atuação junto à pessoa com NEE e atos junto à sociedade.

Sobre a diferença entre inclusão e integração algumas professoras têm dificuldades em responder e as professoras C.P.M.e N.I.N. nunca ouviram falar sobre a diferença.

Professora C.P.M.: “Confesso nunca ter ouvido o termo integração, porém acredito se colocar o portadorde deficiência à interagir com os colegas, ao passo que inclusão é um termo mais amplo que "iguala" em condições de aprendizagem".

Professora N.I.N.: "Integração exclui o aluno, enquanto na inclusão o aluno faz parte do todo da sala de aula".

Nesse discurso podemos perceber a falta de formação por parte dos professores e a precariedade com que a inclusão é tratada na escola. 
3) Uma das grandes barreiras a serem derrubadas está nos preconceitos em relação ao tema. Como você vê esse problema?

Segundo Wernecck:

O preconceito contra os diferentes nasce na infância. No jantar, o Filho pergunta: "Pai, o que é ostomia?" O adulto responde: "Não pensa nisso, é muito triste, come senão a comida vai esfriar". Sem resposta, e vendo sua dúvida desvalorizada, a criança se cala. O que deveria ser esclarecido vira mistério, tabu. Eu sei, nada é tão simples. Mas por não termos sido educados para entender a diversidade como situação natural, hoje relutamos em obedecer leis e seguir regras sociais que dêem às pessoas com deficiência um direito assegurado na Constituição Federal: a cidadania. Por isso defendo a sociedade inclusiva.

A partir dessa reflexão notamos que os preconceitos são ministrados pelo universo adulto e muitas vezes disseminados em ambientes escolares até mesmo pelos próprios professores, que embora não admitam reproduzem discursos discriminatórios e preconceituosos.

Na visão da Gestão escolar o discurso aproxima-se muito da teoria, do ideal, do que sonhamos, porém na prática isso toma outra ótica e o discurso adquire um novo tom. Observam-se os seguintes recortes das respostas da gestão:

Professora A.S.M.: "É uma prática difícil e trabalhosa, causando muita resistência por parte dos de alguns profissionais. Em primeiro lugar tem que ter a sensibilidade humana para dar oportunidade de crescimento para todos, mas ainda há necessidade de vencer o medo de lidar ou dar oportunidades para os deficientes. A escola tem que acolher o aluno e não o aluno a escola".

Professora N.I.H.N: “Os próprios professores são os que criam essa barreira quando conhecem a NEE do aluno.

Quando solicitado apoio pedagógico à gestão escolar, quase sempre os professores escutam como resposta: "deixa lá eles são amparados por lei".

Então, conforme Baptista e Jesus (2011, p. 116):

“Geralmente, as necessidades apontadas pelos gestores e educadores e relatadas pelos técnicos tem relação com a falta de conhecimento teórico pratico de como lidar com os alunos com que apresentem deficiência mental, visual e auditiva. Segundo os técnicos, muitos professores e gestores sentem falta de saber o que e como fazer com que os alunos com necessidades educacionais e relatam a dificuldade de romper com a percepção apenas na deficiência dos alunos". 
Assim, percebemos que a gestão preocupada com a parte burocrática muitas vezes se apropria de discursos vazios deixando de lado a parte pedagógica e não participando de forma ativa da inclusão produzindo um discurso excludente e preconceituoso.

4) Como a convivência entre as pessoas diferentes pode contribuir para as inteligências que cada um de nós possui?

Sobre esse assunto Baptista e Jesus (2011):

\begin{abstract}
"A Declaração de Salamanca, documentos que foi redigido e aprovado na referida conferencia, estabeleceu o direito fundamental de todas as crianças à educação, reconhecendo que possuem características, interesse, capacidades e necessidades de aprendizagem que lhes são próprias, que os sistemas educativos devem ser planejados e os programas aplicados de modo a levar em conta a gama dessas diferentes características e necessidades"
\end{abstract}

Nessa análise, verifica-se com as professoras D.S.C., M.M.S. e A.B. que o discurso está coerente com o pensamento acima, conforme percebemos nos seguintes recortes:

Professora D.S.C.: "A convivência é a forma mais simples e sensível de aprendermos uns com os outros em qualquer situação da nossa vida, não somente com os portadores de NEE, Mas de cultura raça, classe social, opção sexual, e tantos outros é a forma de derrubaras barreiras preconceituosas e mostrarmos, que cada um de nós temos o que oferecer e o que receber do outro. É aprendizado de ambas as partes".

Professora M.M.S.: "As diferenças fazem parte com que tenhamos mais conhecimento, pois aprendemos muito com eles e também na busca de conhecimento".

Professora A.B.: "Quando há integração na turma, as crianças mesmas conseguem interagir e valorizar o seu trabalho do outro, conscientizando-se que cada um tem seu valor".

Podemos verificar que as professoras acreditam que os alunos possam ser incluídos e que a vivência contribua com os fatores da aprendizagem e consigam valorizar as diferenças.

Conforme Carvalho (2006):

Para entender a educação inclusiva deve-se primeiro entender que a proposta não foi concebida apenas para determinados alunos e sim para todos, sem distinção. Entender que somos diferentes. Essa é nossa condição humana. Pensamos de jeito diferente, sentimos com intensidade diferente, agimos de forma diferente, e tudo isso porque vivemos e aprendemos o mundo de forma diferente. 


\section{5) Na sua perspectiva como se constrói uma sociedade Inclusiva e o que muda na vida educacional daqui pra frente?}

Esse último núcleo de significação explicita a perspectiva da Educação Inclusiva e as mudanças na vida educacional. Esse discurso esta coerente entre as professoras D.S.C., A.M.B, J.B.B.e mostra que embora não aconteça formação continuada sobre esse tema a maioria dos professores estão comprometidos com a educação e tem sensibilidade com os alunos com NEE.

Professora D.S.C: “Embora tenhamos um longo caminho pela frente, estamos indo no caminho certo.Existem grandes preconceitos a serem derrubados, mas se cada um de nós plantar a sementinha do bem, certamente alguma delas germinara.A educação tem que ser voltada para todos sem distinção entre os seres humanos. A vida educacional tende a ser solidária, democrática. E nos trará vários beneficio, principalmente para nossos educandos especiais que necessitam do nosso auxilio, carinho, atenção da nossa sensibilidade dedicação".

Professora A.M.B: “ A construção de uma sociedade inclusiva no meu ponto de vista tem que ter como base o respeito a tolerância as diferenças, para termos uma educação justa e igualitária na sua diversidade".

Professora J.B.B.: “Com aceitação do próximo, mas principalmente com respeito, tendo em vista o reflexo direto da escola na sociedade, essa será mais justa e igualitária.

Embora a Educação Inclusiva e a formação continuada da rede pública do município de Vila Nova do Sul sejam precárias, pode-se perceber que mesmo com essas deficiências os professores acreditam na educação de seus alunos e buscam ferramentas para que eles tenham uma educação justa. Sabe-se que esse tema além de conflituoso é bastante delicado, mas não há outra forma de se fazer educação se não for através da inclusão e com a aceitação das diferenças e respeitando a diversidade.

Os resultados aqui apresentados são preliminares e carecem de um maior aprofundamento e novos cruzamentos, entretanto apontam para uma base inicial de como é feita a Educação especial no município de Vila Nova do Sul. Geralmente não promove formação continuada nesta área da Inclusão e quando ofertada pela Secretaria Municipal de Educação, órgão responsável pela educação continuada dos professores municipais, ocorre de forma ampla e insipiente dentro de outro tema.

Diante do panorama pesquisado coloca-se como desafio a formação continuada, a construção conceitual de homem, a cidadania e a Educação Inclusiva, bem como a formação para a diversidade.

\section{Considerações finais}

O estudo feito acerca da pesquisa sobre inclusão escolar está longe de ser um assunto concluído, mas semeia alguns conceitos que se cultivados podem amadurecer e gerar novas práticas de Educação Inclusiva. O caminho percorrido por este estudo não é mais um caminho novo, mas com certeza muito 
já se percorreu na História da Educação Especial, para que nossos alunos com NEE tenham uma educação inclusiva.

De maneira geral, a partir dos resultados obtidos percebe-se que embora exista comprometimento por parte dos professores ainda ocorre a falta de apoio pedagógico e formação continuada na escola e, isso dificulta a possibilidade da inclusão se fazer de maneira benéfica aos alunos com NEE.

Uma das lacunas que essa pesquisa levantou é a falta de consonância entre políticas educacionais inclusivas e a prática realizada em uma escola municipal, uma vez que muito já foi conquistado nessas décadas de luta contra a exclusão das pessoas com NEE e, acreditamos que estamos caminhando, com certeza, para um futuro de conquista para a qualidade da educação com inclusão escolar.

Dessa forma, embora muito se tenha falado sobre Inclusão Escolar, esse processo vai além do simples ato de colocar um aluno com NEE dentro da escola regular, essa ação deve prever um comprometimento coletivo da escola e dos agentes envolvidos, bem como um projeto-políticopedagógico e o planejamento da formação continuada para os servidores da educação.

O debate em torno da inclusão está longe de ser homogêneo, pois envolve realidades sociais, circunstâncias cotidianas e ideologias distintas.

Portanto, percebemos que com formação e comprometimento a educação inclusiva mesmo com sua complexidade poderá acontecer naturalmente de maneira coerente contribuindo assim para mudar a sociedade, incluindo seus cidadãos de maneira mais justa.

\section{Referências Bibliográficas}

ALVES, Zélia Mana Mendes Biasoli; SILVA, Maria Helena G. F. Dias.Análise Qualitativa de Dados de Entrevista: uma proposta. Disponível em: <http://www.revistas.usp.br/paideia/article/viewFile/46422/50178> Acesso em 15 set. 2015.

BAPTISTA, Claudio Roberto; JESUS, Denyse Meirelles de. Avanços em políticas de inclusão: o contexto da educação especial no Brasil e em outros países. Porto Alegre: Mediação, 2009.

CARVALHO, Rosita Edler. Educação inclusiva: com os pingos nos "is". 4. ed. Porto Alegre: Ed. Meditação, 2006.Disponível em:<www.deacoordenacao.blogspot.com/2013>. Acesso em: 15 set. 2015.

Educação Inclusiva. Disponível em: <https://plus.google.com>Acesso em 05 jul. 2015.

FREIRE, Paulo. Pedagogia da autonomia: saberes necessários à prática educativa. 5. ed. Rio de Janeiro: Paz e Terra, 1996

SELAU, Bento. Inclusão na sala de aula. $1^{\circ}$ ed. Porto alegre: Evangraf, 2007. BRASIl. Acesso em: 05 jul. 2015.

WERNECK, Claúdia. Um tiro no pé. Disponível em: <http://www.prefeitura.sp.gov.br>. Acesso em: 15 set.2015. 